\title{
Genetic Divergence Studies in Seedling Progenies of Elephant Foot Yam Amorphophallus paeoniifolius (Dennst.)
}

\author{
A. Reshma, K. Mamatha, B. V. K. Bhagavan, A. Snehalatha rani \\ and D. R. Salomi Suneetha
}

DR YSR Horticultural University, Venkataramannagudem, Andhra Pradesh, India

*Corresponding author

Keywords

Elephant foot yam, $\mathrm{D}^{2}$ technique, Genetic divergence

Article Info

Accepted: 04 September 2020 Available Online: 10 October 2020

\begin{abstract}
A B S T R A C T
An investigation was carried out to assess the genetic divergence in 26 seedling progenies of elephant foot yam utilising Mahalanobis $\mathrm{D}^{2}$ statistic. The experiment was carried out Horticultural Research station, Kovvur, DRYSRHU during 2018 in augumented block design with two checks. All the accessions were grouped into 6 clusters. The cluster II was the largest consisting of 15 accessions followed by cluster III with 5 accessions and cluster I with 3 accessions and cluster IV, V, VI had solitary accessions. Therefore, selection and intercrossing of genotypes involved in these clusters would be useful for inducing variability in the respective characters. Average intra and inter-cluster $\mathrm{D}^{2}$ values among 26 accessions revealed that cluster III recorded maximum intra cluster distance followed by cluster II indicating the existence of diverse genotypes in these clusters. While, inter cluster differences were maximum between cluster III and cluster V followed by I and VI, III and VI, III and IV, I and III and IV and VI indicating that the genotypes from these clusters can be selected for future breeding programme to produce heterotic hybrids.
\end{abstract}

\section{Introduction}

Amorphophallus paeoniifolius (Dennst.) is a herbaceous, perennial, monoecious $\mathrm{C}_{3}$ crop. It is basically a crop of South Eastern Asian origin. It serves as a source of protein as well as starch. It has been used as a local staple food in many countries like Philippines, Java, Indonesia, Sumatra, Malaysia, Bangladesh, India, China and South Eastern Asian countries. Owing to its production potential and popularity as a vegetable in various delicious Indian cuisines, it is commercially cultivated in India in the states of Andhra
Pradesh, West Bengal, Bihar, Gujarat, Kerala, Tamil Nadu, Maharashtra, Uttar Pradesh and Jarkhand. In the Northern and Eastern states of India local cultivars grown in wild form are generally being used for making vegetable pickles and indigenous for various ailments. The corms are usually eaten as vegetable after boiling or baking and are rich in calcium, (50 $\left.\mathrm{mg} \mathrm{g}^{-1}\right)$, phosphorus $\left(34 \mathrm{mg} \mathrm{g}^{-1}\right)$ and vitamin A $\left(260 \mathrm{IU} \mathrm{g}^{-1}\right)$. The leaves of elephant foot yam are rich in Vit A and used as a vegetable by local tribes in India (Raghu et al., 1999. It is an important tuber crop that offers excellent scope for adaptation as a cash crop due to its 
higher yield potential and longer shelf life than other vegetable crops. Elephant foot yam has got great potentiality to provide nutritional security to the developing countries along with its medicinal aspects. It is a vegetatively propagated crop and hence genetic variability among the accessions is very limited. Characterization of germplasm materials helps to ensure an efficient and effective use of genotypes for further crop improvement. Mahalanobis $\mathrm{D}^{2}$ analysis helps in assessing the diversity among the genotypes and to select the divergent parents for future breeding programmes (Mahalanobis, 1936).

Though it is reported to be a highly cross pollinated crop, sexual reproduction is reported to be very rare due to scarce flowering, non -synchronization of flowers and the presence of extreme protogyny and hence the vegetative propagation is in common practice. Hence, absence of cross breeding and continuous vegetative propagation has led to the stagnation in the genetic improvement in this species (Sreekumari, 2000). In spite of reproductive barriers, occasional success in seed formation is observed, under coastal alluvial soils of Andhra Pradesh, where elephant foot yam is left un-harvested for 2-3 years. Such seeds are raised and the seedlings are raised and maintained at Horticultural Research Station, Kovvur. A. paeoniifolius being essential for food security in many developing countries, there is a need to broaden the genetic base in order to develop the varieties for wider adoptability.

\section{Materials and Methods}

The experimental material consists of 24 open pollinated seedling progenies of elephant foot yam along with two checks, which were being maintained at Horticultural Research Station, Kovvur. The experiment was laid out in augmented block design consisting of four blocks with six entries per each block. Standard package of practices were followed to raise the crop. The observations were recorded on five randomly selected plants and the mean values were subjected to Observations were recorded on 24 quantitative characters and data was subjected to statistical analysis using Mahalanobis $\mathrm{D}^{2}$ (1936) statistic to assess the genetic divergence. The genotypes were grouped on the basis of minimum generalized distance using the Tocher's method (Rao, 1952).

\section{Results and Discussion}

The success in obtaining highly variable genotypes and creating greater variability for efficient selection in a breeding programme depends to a larger measure on the degree of divergence

Analysis of variance revealed the significant difference for all the 24 quantitative characters studied, indicating the existence of wide genetic divergence among them. Based on the $\mathrm{D}^{2}$ values, 26 accessions were grouped into six clusters (Table 1). This suggested the presence of high degree of divergence in the material studied. Maximum number of genotypes were accommodated in cluster II (15) followed by cluster III (5) and cluster I (3) and remaining clusters (IV, V, VI) were mono-genotypic. The mutual relationship between the clusters is represented diagrammatically (Figure 1) by taking the average intra and inter cluster $\mathrm{D}^{2}$ values. were presented in Table 2 and Figure 2. The intra cluster $\mathrm{D}^{2}$ values ranges from 0 to 2595.22 and cluster III recorded the maximum $\mathrm{D}^{2}$ value (2595.22). followed by cluster II (1896.96). Intra cluster distances were not observed in cluster IV, V, VI as they were solitary clusters.

The inter cluster $\mathrm{D}^{2}$ values ranged from 1481.52 to 11730.96 . The maximum inter cluster $\mathrm{D}^{2}$ values was between cluster III and 
cluster V (11730.96) followed by cluster I and cluster VI (10269.31) and cluster III and VI (9555.37), cluster III and cluster IV (8626.39), cluster I and cluster III (6690.30), cluster IV and VI (5885.36). While the lowest inter-cluster $\mathrm{D}^{2}$ value was recorded between the cluster I and V (2750.72). The information regarding nearest and farther cluster indicated that cluster V (2750.72) was closely related to cluster I and cluster VI (10269.31) was distantly related to cluster I. Cluster II exhibited close proximity (3482.28) with cluster IV and it exhibited wide diversity with cluster V (4981.42).Cluster III exhibited close proximity (8626.39) to cluster IV, while it was distantly related to cluster V (11730.96).Cluster IV was closely related to cluster V (1481.52), while it was distantly related to cluster VI (5885.36). Finally, the nearest cluster for cluster VI was cluster II (3764.34), while the farthest cluster was cluster I (10269.31).

Based on the inter cluster distances, it was evident that all the clusters were distantly related indicating the genetic divergence with a scope to get good recombination through advanced breeding techniques like protoplast fusion or somatic hybridization.

Table.1 Distribution of elephant foot yam seedling progenies into different clusters

\begin{tabular}{|c|c|l|}
\hline Cluster No. & $\begin{array}{l}\text { Number of } \\
\text { accessions }\end{array}$ & \multicolumn{1}{|c|}{ Name of the accessions } \\
\hline I & 3 & Gajendra, Sree padma, OP/14- 61 \\
\hline II & 15 & $\begin{array}{l}\text { OP/14-20, OP/14-24, OP/14-11. OP/14-21, OP/14-17, OP/14-6, } \\
\text { OP/14-2, OP/14-44, OP/14-12, OP/14-47, OP/14-31, OP/14-42, } \\
\text { OP/14-63, OP/14-27, OP/14-22 }\end{array}$ \\
\hline III & 5 & OP/14-28, OP/14-65, OP/14-26,OP/14-1, OP/14-59 \\
\hline IV & 1 & OP/14-34 \\
\hline V & 1 & OP/14-57 \\
\hline VI & 1 & OP/14-3 \\
\hline
\end{tabular}

Table.2 Average inter and intra - cluster (diagonal) distance D2 values in elephant foot yam

\begin{tabular}{|c|c|c|c|c|c|c|}
\hline & & & & & \\
\hline Cluster I & $\mathbf{1 0 6 3 . 8 9}$ & 4574.35 & 6690.30 & 2976.77 & 2750.72 & 10269.31 \\
\hline Cluster II & & $\mathbf{1 8 7 6 . 9 2}$ & 4765.85 & 3482.28 & 4981.42 & 3764.34 \\
\hline Cluster III & & & $\mathbf{2 5 9 5 . 2 2}$ & 8626.39 & 11730.96 & 9555.37 \\
\hline Cluster IV & & & & $\mathbf{0 . 0 0}$ & 1481.52 & 5885.36 \\
\hline Cluster V & & & & & $\mathbf{0 . 0 0}$ & 6589.52 \\
\hline Cluster VI & & & & & & $\mathbf{0 . 0 0}$ \\
\hline
\end{tabular}


Table.3 Cluster means for yield and its components in elephant foot yam

\begin{tabular}{|c|c|c|c|c|c|c|c|}
\hline $\begin{array}{l}\text { S. } \\
\text { no }\end{array}$ & Charcters & Cluster-I & Cluster-II & Cluster-III & Cluster-IV & Cluster-V & Cluster-VI \\
\hline 1 & Plant height $(\mathrm{cm})$ & 59.37 & 58.03 & 67.25 & 46.65 & 39.54 & 30.32 \\
\hline 2 & Pseudo-stem height $(\mathrm{cm})$ & 52.67 & 51.28 & 60.93 & 38.90 & 33.51 & 24.09 \\
\hline 3 & $\begin{array}{l}\text { Thickness of pseudo-stem base } \\
(\mathrm{cm})\end{array}$ & 7.99 & 9.38 & 11.41 & 7.43 & 6.92 & 8.69 \\
\hline 4 & Leaves per rachis & 1.50 & 1.47 & 1.44 & 1.25 & 1.24 & 1.01 \\
\hline 5 & Leaflets per rachis & 81.76 & 117.38 & 150.00 & 92.12 & 65.73 & 126.98 \\
\hline 6 & Primary partitions & 3.00 & 3.60 & 3.00 & 3.20 & 3.00 & 3.00 \\
\hline 7 & Secondary partitions & 6.00 & 5.40 & 5.96 & 6.00 & 6.00 & 6.00 \\
\hline 8 & Tertiary partitions & 6.52 & 6.40 & 7.10 & 7.49 & 5.23 & 6.80 \\
\hline 9 & Length of primary partition $(\mathrm{cm})$ & 40.95 & 38.18 & 53.60 & 13.94 & 31.08 & 40.55 \\
\hline 10 & Breadth of primary partition $(\mathrm{cm})$ & 27.44 & 25.38 & 31.58 & 6.17 & 22.17 & 31.98 \\
\hline 11 & Leaflets per primary partition & 7.37 & 7.09 & 8.29 & 6.65 & 7.18 & 4.65 \\
\hline 12 & Length of largest leaflet $(\mathrm{cm})$ & 13.43 & 14.15 & 16.47 & 17.10 & 9.81 & 13.44 \\
\hline 13 & Breadth of largest leaflet $(\mathrm{cm})$ & 5.86 & 6.24 & 7.63 & 4.88 & 4.65 & 5.43 \\
\hline 14 & Days to senescence & 207.60 & 165.69 & 192.80 & 190.00 & 188.00 & 140.80 \\
\hline 15 & Fresh weight of corm per plant $(\mathrm{kg})$ & 1.68 & 1.07 & 1.94 & 0.83 & 0.63 & 0.23 \\
\hline 16 & Height of corm $(\mathrm{cm})$ & 9.78 & 10.26 & 12.50 & 7.54 & 8.25 & 8.53 \\
\hline 17 & Diameter of corm $(\mathrm{cm})$ & 15.54 & 15058 & 18.24 & 11.87 & 12.79 & 11.30 \\
\hline 18 & Cormels per corm & 1.17 & 0.85 & 0.88 & 1.09 & 0.99 & 0.89 \\
\hline 19 & Weight of cormels per plant & 11.55 & 14.52 & 14.12 & 12.91 & 12.51 & 20.22 \\
\hline 20 & Length of cormel $(\mathrm{cm})$ & 3.63 & 3.64 & 3.56 & 3.56 & 4.36 & 5.46 \\
\hline 21 & Thickness of cormel (cm) & 9.18 & 6.24 & 5.35 & 7.58 & 7.26 & 8.13 \\
\hline 22 & Yield (t/ha) & 46.56 & 29.85 & 53.75 & 22.94 & 17.39 & 6.42 \\
\hline 23 & Starch $(\%)$ & 30.95 & 29.30 & 29.71 & 22.35 & 30.12 & 28.52 \\
\hline 24 & Oxalates (\%) & 0.21 & 0.31 & 0.34 & 0.32 & 0.29 & 0.33 \\
\hline
\end{tabular}


Table.4 Contribution of characters towards divergence

\begin{tabular}{|c|l|c|c|}
\hline S.no & Source & Contribution (\%) & $\begin{array}{c}\text { Number of times } \\
\text { ranked first }\end{array}$ \\
\hline $\mathbf{1}$ & Plant height $(\mathrm{cm})$ & 2.15 & 7 \\
\hline $\mathbf{2}$ & Pseudo-stem height $(\mathrm{cm})$ & 1.85 & 6 \\
\hline $\mathbf{3}$ & Leaflets per rachis & 41.54 & 135 \\
\hline $\mathbf{4}$ & Length of primary partition $(\mathrm{cm})$ & 6.77 & 22 \\
\hline $\mathbf{5}$ & Breadth of primary partition $(\mathrm{cm})$ & 0.62 & 113 \\
\hline $\mathbf{6}$ & Days to senescence & 34.77 & 10 \\
\hline $\mathbf{7}$ & Weight of cormels per corm $(\mathrm{g})$ & 3.08 & 27 \\
\hline $\mathbf{8}$ & Yield $(\mathrm{t} / \mathrm{ha})$ & 8.31 & 3 \\
\hline $\mathbf{9}$ & Starch $(\%)$ & 0.92 & \\
\hline
\end{tabular}

Fig.1 Dendrogram showing the clustering pattern of elephant foot yam seedling progenies

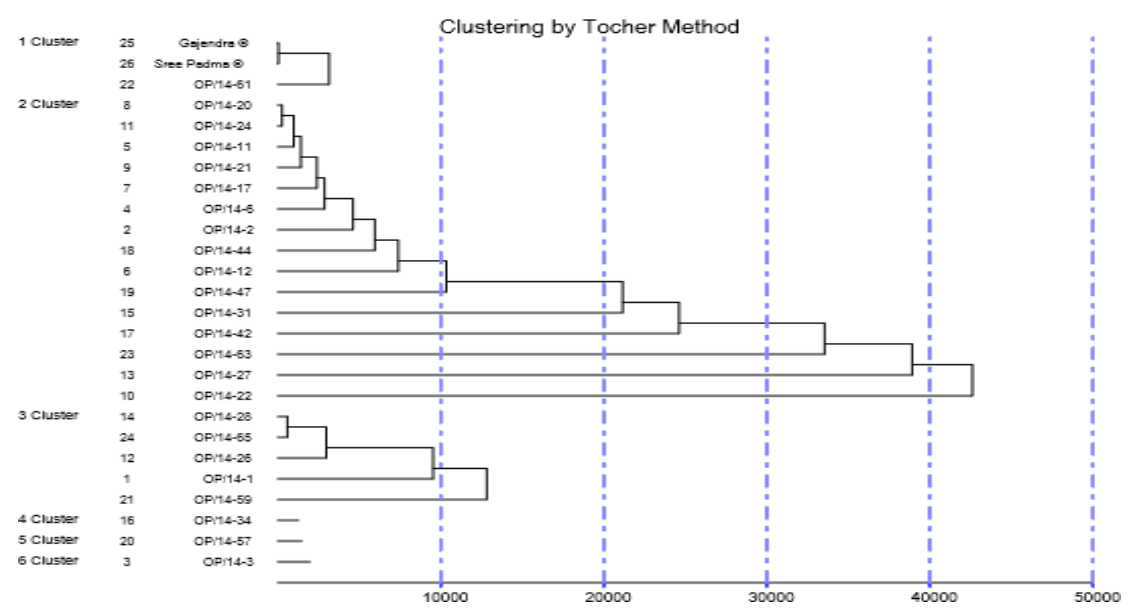

Fig.2 Inter and Intra-cluster distances among different elephant foot yam accessions

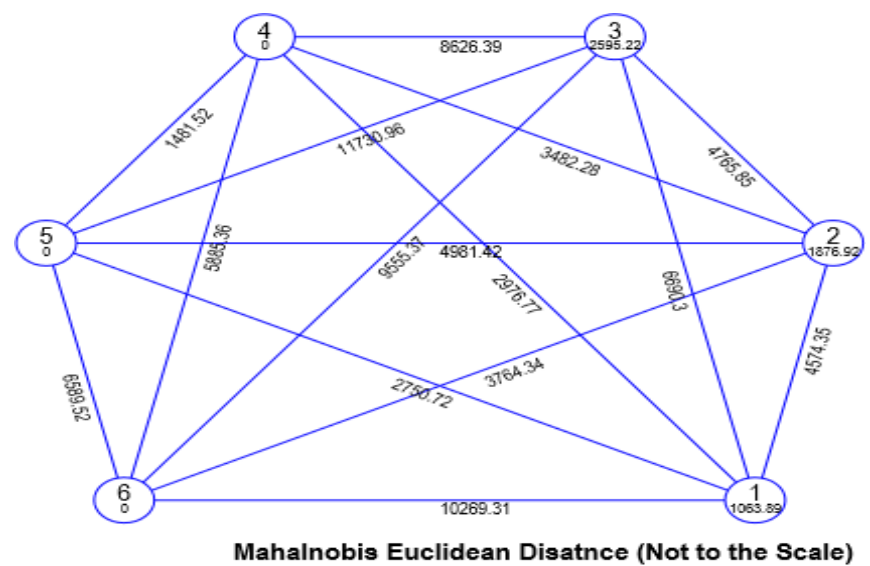


The highest inter cluster value between cluster III and cluster V (11730.96) followed by cluster I and cluster VI (10269.31), cluster III and VI (9555.37), cluster III and cluster IV (8626.39), cluster I and cluster III (6690.30), cluster IV and VI (5885.36) can be expected to exert high heterotic effect in the hybrids when crossed and consequently may generate desirable segregants, thus broad spectrum of variability can be created in the ensuing generation.

This variability may be helpful in future selections and crop improvement programmes. Based on cluster mean values, cross combinations between the clusters can be made either through advanced breeding techniques or through crossing programmes which may give good recombinants for high yield. For a successful breeding programme selection of genetically diverse parents is an important pre-requisite so as to obtain better and desirable recombinants.

The cluster mean values (Table 3) for plant height, pseudo-stem height, thickness of pseudo-stem base, leaflets per rachis, length of primary partition, leaflets per primary partition, breadth of largest leaflet, fresh weight of corm, height of corm, diameter of corm, yield per hectare, oxalates percent were highest in case of cluster III with five accessions. The cluster mean values for primary partitions were highest in cluster II with 15 accessions. The cluster mean values for number of leaves per rachis, number of cormels per corm, thickness of cormel and starch percent were highest in cluster I with one 3 accessions. Hence, revealed that quite different genetic makeup of the genotypes included in these clusters indicating the important role of these characters in the genetic divergence.

Contribution of individual characters towards divergence was calculated as per the method given by Singh and Choudary (1977) and has been presented in table 4. Among all the characters, number of leaflets per rachis has contributed maximum towards divergence $(41.54 \%)$ followed by days to senescence which contributed $34.77 \%$. Yield per hectare, length of primary partition, weight of cormels per plant, plant height, pseudo-stem height, starch content and breadth of primary partition has contributed $8.31 \%, 6.77 \%$, $3.08 \%, \quad 2.15 \%, \quad 1.85 \%, \quad 0.92 \%, \quad 0.62 \%$ respectively towards divergence. Remaining characters ie., thickness of pseudo-stem base, number of leaves per rachis, primary, secondary and tertiary partitions, leaflets per primary partition, length and breadth of largest leaflet, fresh weight of corm, height of corm, diameter of corm, number of cormels per corm, length of cormel and thickness of cormel and oxalates percent did not contribute anything to the diversity.

In conclusions the highest inter cluster distance was observed between cluster III and V followed by cluster I and VI, III and VI, III and IV, I and III, IV and VI respectively. Thus, crossing between genotypes of cluster III and $\mathrm{V}$ might provide good chance for transgressive segregates in the segregating generations and may end up in some promising accessions. Cluster means for different clusters indicated that cluster III had highest mean values for plant height, pseudostem height, thickness of pseudo-stem base, leaflets per rachis, length of primary partition, leaflets per primary partition, breadth of largest leaflet, fresh weight of corm, height of corm, diameter of corm, yield per hectare, oxalates percent. Cluster I was the best source for number of leaves per rachis, number of cormels per corm, thickness of cormel and starch percent. Thus, broad spectrum of variability can be created in the ensuing generation which may be helpful in future selections and crop improvement programmes. 


\section{References}

Mahalanobis, P.C., (1936). On the generalised distance in statistics. Proceedings of National Institute of Science, India. 2: 49-55.

Raghu, R.V., Deepa, C., Sundaran, K. 1999. A study of soorana (Amorphophallus paeoniifolius) the king of tubers. Tropical Tuber Crops in Food security and Nutrition. 12 (7): 10-14.

Rao, C. R. (1952). Advanced statistical methods in biometrical research. Ed. J. John Wiley and Sons, Inc. New York: 198-201.

Singh, R.K and Choudhary, B.D.1977. Biometrical Techniques in Quantitaive Genetic Analysis. Kalyani Publishers, Ludhiana. 288.

Sreekumari, M.T. 2000. Flowering, intervarietal hybridisation, selfing and seed production in elephant foot yam. Journal of Root crops. 26(2):18-22.

\section{How to cite this article:}

Reshma, A., K. Mamatha, B. V. K. Bhagavan, A. Snehalatha rani and Salomi Suneetha, D. R. 2020. Genetic Divergence Studies in Seedling Progenies of Elephant Foot Yam Amorphophallus paeoniifolius (Dennst.). Int.J.Curr.Microbiol.App.Sci. 9(10): 41-47. doi: https://doi.org/10.20546/ijcmas.2020.910.006 